\title{
Urinary Voiding as a Tool to Reduce Radiation Exposure in the Nuclear Stress Lab
}

\author{
Santosh Desai ${ }^{1}$, Samuel Unzek ${ }^{1}$, Reza Arsanjani ${ }^{1}$, Stephanie Krause ${ }^{2}$, Ba Nguyen ${ }^{2}$, Fadi Shamoun ${ }^{1}$, and William Pavlicek ${ }^{2}$ \\ ${ }^{1}$ Division of Cardiovascular Disease, Mayo Clinic Arizona, Scottsdale, Arizona; and ${ }^{2}$ Department of Radiology, Mayo Clinic Arizona, \\ Scottsdale, Arizona
}

\begin{abstract}
Nuclear stress testing is being increasingly justified in the cardiovascular risk stratification of patients. Radiation is an important consideration, and attempts to minimize exposure should be implemented. Efficiency and cost effectiveness are cornerstones in the delivery of quality patient care and should also be considered when implementing change. Methods: We studied 88 consecutive patients who presented to our stress lab for pharmacologic nuclear stress testing. A single-day rest-andstress protocol with low-level exercise was used for all patients. After the stress portion of the examination, we measured Geiger counter activity above the bladder area to establish a baseline. Patients were then allowed to void, and repeat measurements were taken. Results: We detected a $16.9 \%$ reduction from baseline radiation levels above the bladder area after voiding. Conclusion: Urinary voiding is a simple, cost-effective strategy at reducing radiation exposure in the nuclear stress lab.
\end{abstract}

Key Words: cardiology (clinical); quality assurance; radiation safety; quality; radiation; voiding

J Nucl Med Technol 2019; 47:160-162

DOI: 10.2967/jnmt.118.212548

$\mathbf{N}$ uclear myocardial perfusion imaging has been instrumental in the risk stratification of patients suspected of having ischemic heart disease. Furthermore, the widespread use of ${ }^{99 \mathrm{~m}} \mathrm{Tc}$-labeled radiopharmaceuticals has improved the efficiency of the stress testing process ( $I$ ). Despite advances in instrumentation such as cardiac cadmium-zinc-telluride cameras (2) and improvements in signal processing such as iterative reconstruction (3), concerns regarding radiation safety remain. As more of these noninvasive myocardial perfusion tests are ordered, particularly multiple tests in the same patient, radiation exposure may not be negligible. Although individual risk is small, increasing use of myocardial perfusion imaging has the potential to affect future cancer risk for the greater population (4). Furthermore, if the recommendations outlined in the 2010 American Society of

Received Jun. 2, 2018; revision accepted Nov. 13, 2018.

For correspondence or reprints contact: Santosh Desai, 13400 E Shea Blvd., Division of Cardiology, Scottsdale, AZ 85259.

E-mail: skdesai2@gmail.com

Published online Jan. 25, 2019.

COPYRIGHT @ 2019 by the Society of Nuclear Medicine and Molecular Imaging.
Nuclear Cardiology information statement are followed, the expectation is for a total radiation exposure of less than or equal to $9 \mathrm{mSv}$ in half of all myocardial perfusion imaging studies by 2014 (5).

${ }^{99 \mathrm{~m}} \mathrm{Tc}$-tetrofosmin is one of the most commonly used tracers in myocardial perfusion imaging studies. One particular area in which ${ }^{99 \mathrm{~m}} \mathrm{Tc}$-labeled radiopharmaceuticals have shown significant activity is the urinary bladder (6). Studies show that for an administered dose of $11.1 \mathrm{MBq}$ $(0.3 \mathrm{mCi})$ of ${ }^{99 \mathrm{~m}} \mathrm{Tc}$-tetrofosmin, the effective dose for a $3.5-\mathrm{h}$ bladder voiding period would be $9.9 \mathrm{mSv}$ (1 rad) at rest or $7.9 \mathrm{mSv}(0.8 \mathrm{rad})$ after exercise (6). Statistical limitations make it challenging to evaluate cancer risk in humans, but based on the BEIR VII lifetime risk model, it is predicted that approximately 1 in 100 individuals would develop cancereither solid-organ or leukemia-from a dose of $0.1 \mathrm{~Sv}$ above background (7).

Understanding biodistribution and dosimetry is crucial to patient-centered radiation safety measures and can lead to advances in quality improvement. After studying the biodistribution properties of ${ }^{99 \mathrm{~m}} \mathrm{Tc}$-tetrofosmin, we hypothesized that allowing urinary voiding before patient discharge from the stress lab would result in less radiation exposure. This simple, cost-free protocol adjustment has the potential to improve patient safety.

\section{MATERIALS AND METHODS}

We studied 88 patients who presented to our nuclear stress lab. Institutional review board approval was requested, but the project was considered exempt by the board since there was no significant deviation from the established protocol and the project is considered quality improvement. The requirement to obtain informed consent was waived. The study qualified for exemption 45 CFR 46.101(b) (1) from 45 CFR part 46 requirements published by the Office for Human Research Protections (8). Patient demographics are represented in Figure 1. Most the patients were male and between the ages of 60 and $79 \mathrm{y}$. More than half the patients had a body mass index less than or equal to 30 . Furthermore, a majority of the patients also had normal renal function.

Patients were included in the study only if they were able to void. All subjects underwent a single-day, rest-and-stress ${ }^{99 \mathrm{~m}} \mathrm{Tc}-$ tetrofosmin protocol conforming to the American Society of Nuclear Cardiology guidelines (9). Patients were instructed to fast for at least $3 \mathrm{~h}$ and to avoid caffeinated products for $12 \mathrm{~h}$ before the test. All myocardial perfusion imaging scans were acquired with a dedicated 


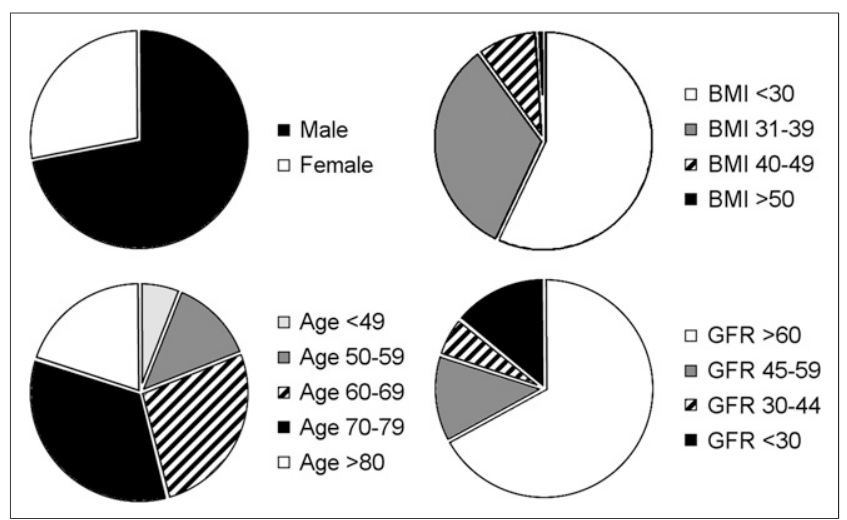

FIGURE 1. Patient demographics detailing sex, age, body mass index (BMI), and glomerular filtration rate (GFR).

cardiac SPECT camera using cadmium-zinc-telluride crystals and tungsten collimators (D-SPECT; Biosensors International). Patients were given a standard intravenous dose of regadenoson, $0.4 \mathrm{mg}$ (Lexiscan; Astellas Pharma Inc), and followed a low-level exercise protocol. Once the stress portion of the examination was performed, patients were instructed to eat to improve image quality and, for the purpose of this study, to resist the urge to void. On returning from their meal, a Geiger counter was used to detect radiation levels above the bladder area. Patients were then allowed to void. Radiation detection was then performed again immediately after voiding. Poststress images were then acquired, and the standard protocol was completed.

Exposure rate data were analyzed with respect to the excess lifetime risk of developing a radiation-induced cancer based on our average administered dose of 1,610 MBq (43.5 mCi) (stress and rest). According to the International Commission on Radiological Protection publication 103, Table A.4.1, for a population aged $18-64$ y the risk is approximately 17 cases per 10,000 individuals exposed to an average of $17 \mathrm{mSv}(10)$.

\section{RESULTS}

On returning to the stress lab, study patients did comply with the request to not void during their break. Of the 88 consecutive patients measured, we detected an average of $0.13 \mathrm{mSv} / \mathrm{h}$ above the bladder area before voiding and $0.108 \mathrm{mSv} / \mathrm{h}$ immediately after voiding. This is a $16.9 \%$ reduction in patients receiving an average of $1,610 \mathrm{MBq}$ (43.5 mCi) of ${ }^{99 \mathrm{~m}} \mathrm{Tc}$-tetrofosmin for their examination, including a rest dose of $320 \mathrm{MBq}(8.6 \mathrm{mCi})$ and a stress dose of 1,300 MBq (35.1 mCi) (Fig. 2). An estimated lifetime risk of developing a radiation-induced cancer from using our proposed protocol is lowered from 17 to approximately 14 cases per 10,000 individuals.

\section{DISCUSSION}

Excellent cardiac uptake and retention, paired with efficient clearance from other organs, makes $99 \mathrm{~m}$ Tc-tetrofosmin a choice agent for myocardial perfusion imaging (6). Significant activity is often observed in the urinary bladder according to previous biodistribution studies ( 6 ). Of note, previous studies also establish a higher rate of urinary clearance in the

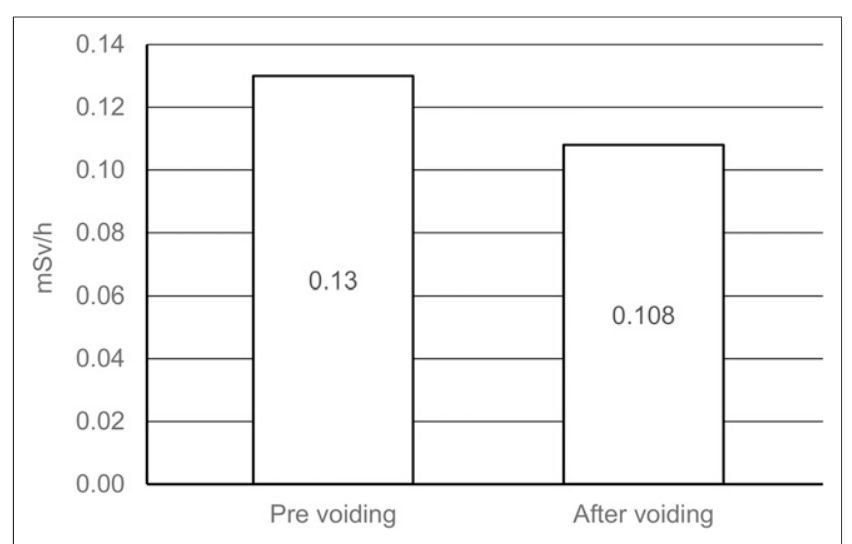

FIGURE 2. Dose reduction measured at level of bladder before and after voiding.

resting study than in the exercise study (6). Urinary voiding before the acquisition of the stress images is ideal. The patients have had the opportunity to hydrate during their brief break after the regadenoson injection. Hydration also allows for more radiation waste to build up in the urinary bladder.

There are many ways to reduce radiation exposure in the cardiac stress lab (Table 1). Judicious stress test ordering and appropriate patient selection would be the obvious mechanisms for reducing radiation exposure. Some labs have opted for stress-only imaging initially, then bringing the patient back for rest images only if needed. Certainly, the newer-generation cameras along with more efficient acquisition and reconstruction technology is improving efficiency in the lab and reducing radiation exposure. However, the latest technology may be cost and resource intensive, which may not be feasible for all labs. Each individual stress lab has to perform cost-benefit analyses to see which dose reduction strategy is optimal for its unique situation.

We do note that our study population was older than the range given in the risk estimate by the International Commission on Radiological Protection. Although we purport that the

TABLE 1

Outlining Some Current Strategies for Dose Reduction

\begin{tabular}{ll}
\hline \multicolumn{1}{c}{ Dose reduction strategy } & $\begin{array}{c}\text { Approximated dose } \\
\text { reduction }\end{array}$ \\
\hline $\begin{array}{l}\text { Appropriate patient selection } \\
\text { Stress-only SPECT imaging }\end{array}$ & $\begin{array}{l}\text { Significant reduction } \\
\text { Significant reduction }\end{array}$ \\
$\begin{array}{l}\text { Solid-state cameras } \\
\text { PET (3-dimensional mode } \\
\text { of operation with lutetium } \\
\text { oxyorthosilicate system) }\end{array}$ & $50 \%(11,12)$ \\
\hline $\begin{array}{l}\text { Iterative reconstruction } \\
\text { Multiple detector systems (17) }\end{array}$ & Significant reduction \\
$\begin{array}{l}\text { Resolution recovery software } \\
\text { Collimator (general-purpose } \\
\text { collimator acquisition) }\end{array}$ & Significant reduction \\
$\begin{array}{l}\text { Collimators for cardiac } \\
\text { imaging (19,20) }\end{array}$ & $50 \%(18)$ \\
\hline $\begin{array}{l}\text { Continuous acquisitions } \\
\text { Voiding }\end{array}$ & Minor \\
\hline
\end{tabular}


theoretic risk is reduced by 3 cases per 10,000 patients, this may be an overestimate.

\section{CONCLUSION}

Our data suggest that adding a simple urinary voiding break to the standard stress protocol can also reduce patient radiation exposure. Although the small sample size of patients can certainly be considered a limitation of this study, future studies can easily enroll more patients without using significant resources.

In an era when myocardial perfusion imaging is being used more often, improving radiation safety and reducing patient radiation exposure are of paramount importance. Implementing a simple protocol adjustment and allowing the patient to void after adequate hydration can reliably reduce radiation exposure. This technique is not resource-intensive and can be done with minimal-to-no cost.

\section{DISCLOSURE}

No potential conflict of interest relevant to this article was reported.

\section{REFERENCES}

1. Jain D. Technetium-99m labeled myocardial perfusion imaging agents. Semin Nucl Med. 1999;29:221-236.

2. Lima RS, Peclat T, Souza A, et al. Prognostic value of a faster, low-radiation myocardial perfusion SPECT protocol in a CZT camera. Int J Cardiovasc Imaging. 2017;33:2049-2056.

3. Brambilla M, Lecchi M, Matheoud R, et al. Comparative analysis of iterative reconstruction algorithms with resolution recovery and new solid state cameras dedicated to myocardial perfusion imaging. Phys Med. 2017;41:109-116.

4. Berrington de Gonzalez A, Kim K, Smith-Bindman R. Myocardial perfusion scans: projected population cancer risks from current levels of use in the United States. Circulation. 2010;122:2403-2410.

5. Cerqueira MD, Allman K, Ficaro E, et al. Recommendations for reducing radiation exposure in myocardial perfusion imaging. J Nucl Cardiol. 2010;17:709-718.

6. Higley B, Smith F, Smith T, et al. Technetium-99m-1,2-bis[bis (2-ethoxyethyl) phosphino]ethane: human biodistribution, dosimetry and safety of a new myocardial perfusion imaging agent. J Nucl Med. 1993;34:30-38.
7. National Research Council. Health Risks from Exposure to Low Levels of Ionizing Radiation: BEIR VII Phase 2. Washington, DC: The National Academies Press; 2006.

8. Human Subject Regulations Decision Charts. U.S. Department of Health and Human Services website. https://www.hhs.gov/ohrp/sites/default/files/full-2016decision-charts.pdf. Published February 16, 2016. Accessed February 19, 2019.

9. Henzlova MJ, Duvall W, Einstein A, Travin M, Verberne H. ASNC imaging guidelines for SPECT nuclear cardiology procedures: Stress, protocols, and tracers. J Nucl Cardiol. 2016;23:606-639.

10. The 2007 recommendations of the International Commission on Radiological Protection: ICRP publication 103. Ann ICRP. 2007;37:1-332.

11. Berman DS, Kang X, Tamarappoo B, et al. Stress thallium-201/rest technetium$99 \mathrm{~m}$ sequential dual isotope high-speed myocardial perfusion imaging. JACC Cardiovasc Imaging. 2009;2:273-282.

12. Slomka PJ, Patton J, Berman D, Germano G. Advances in technical aspects of myocardial perfusion SPECT imaging. J Nucl Cardiol. 2009;16:255-276.

13. Bateman TM, Heller G, McGhie A, et al. Multicenter investigation comparing a highly efficient half-time stress-only attenuation correction approach against standard rest stress Tc-99m SPECT imaging. J Nucl Cardiol. 2009;16:726-735.

14. DePuey EG, Gadiraju R, Clark J, Thompson L, Anstett F, Shwartz S. Ordered subset expectation maximization and wide beam reconstruction "half-time" gated myocardial perfusion SPECT functional imaging: a comparison to "fulltime" filtered backprojection. J Nucl Cardiol. 2008;15:547-563.

15. DePuey EG, Bommireddipalli S, Clark J, Thompson L, Srour Y. Wide beam reconstruction "quarter-time" gated myocardial perfusion SPECT functional imaging: a comparison to "fulltime" ordered subset expectation maximum. J Nucl Cardiol. 2009; 16:736-752.

16. Venero CV, Heller G, Bateman T, et al. A multicenter evaluation of a new postprocessing method with depth-dependent collimator resolution applied to full-time and half-time acquisitions without and with simultaneously acquired attenuation correction. J Nucl Cardiol. 2009;16:714-725.

17. He X, Links J, Gilland K, Tsui B, Frey E. Comparison of 180 and 360 acquisition for myocardial perfusion SPECT with compensation for attenuation, detector response, and scatter: Monte Carlo and mathematical observer results. $\mathrm{J} \mathrm{Nucl}$ Cardiol. 2006;13:345-353.

18. Cherry S, Sorenson J, Phelps M. Physics in Nuclear Medicine. Philadelphia, PA: Elsevier Health Sciences; 2003:201.

19. Marie PY, Djaballah W, Franken P, et al. OSEM reconstruction, associated with temporal Fourier and depth-dependent resolution recovery filtering, enhances results from sestamibi and ${ }^{201}$ TI 16-interval gated SPECT. J Nucl Med. 2005;46: 1789-1795.

20. Daou D, Pointurier I, Coaguila C, et al. Performance of OSEM and depth-dependent resolution recovery algorithms for the evaluation of global left ventricular function in ${ }^{201}$ TI gated myocardial perfusion SPECT. J Nucl Med. 2003;44: $155-162$.

21. Bieszk JA, Hawman E. Evaluation of SPECT angular sampling effects: continuous versus step-and-shoot acquisition. J Nucl Med. 1987;28:1308-1314. 